\title{
EFICIÊNCIA DA DELTAMETRINA E DA PERMETRINA, EM APLICAÇÃO TERRESTRE, CONTRA OS LEPIDÓPTEROS Thyrinteina arnobia (GEOMETRIDAE) E Nystalea nyseus (NOTODONTIDAE) NO TRÓPICO ÚMIDO.
}

\author{
José Cola ZANUNCIO., Raul Narciso Carvalho GUEDES., Adalton Pinheiro \\ CRUZ., Teresinha V. ZANUNCIO.
}

\begin{abstract}
RESUMO - Avaliou-se a eficiência dos piretróides deltametrina e permetrina em lagartas e mariposas de Thyrinteina arnobia (Stoll, 1782) (Lepidoptera: Geometridae) e Nystalea nyseus (Cramer, 1775) (Lepidoptera: Notodontidae). Cinco pontos de amostragem foram estabelecidos em cada parcela e as avaliações feitas 24,48 e 72 horas após a aplicação dos inseticidas. Após a última avaliação foi feita uma pulverização a alta dosagem nos pontos de amostragem e contado o número total de insetos remanescentes nesses pontos para permitir o cálculo da porcentagem de eficiência em relação à mortalidade da testemunha. Evidenciou-se rápida ação larvicida da deltametrina e permetrina contra as duas espécies desfolhadoras. Esses inseticidas contudo, não foram eficientes contra os adultos dessas espécies e mostraram baixa seletividade $\mathrm{cm}$ favor de outros insetos, principalmente moscas parasitóides.
\end{abstract}

Palavras-Chave: Lepidoptera, controle, monitoramento de insetos, Thyrinteina arnobia, Nystalea nyseus, deltametrina, permetrina.

Efficiency of Deltamethrin and Permethrin, in Terrestrial Application, Against the Lepidopterous Thyrinteina arnobia (Geometridae) and Nystalea nyseus (Notodontidae) in the Humid Tropic.

\begin{abstract}
The efficiency of deltamethrin and permethrin was evaluated against caterpillars and moths of the eucalyptus leaf caterpillars species Thyrinteina arnobia (Lepidoptera: Geometridae) and Nystalea nyseus (Lepidoptera: Notodontidae). Five sampling points were established in each experimental unit and the evaluations were performed after 24,48 and 72 hours after insecticide aplication. A high dosage spraying was made after the last evaluation and the number of dead insects was counted in each sampling point and the efficiency $(\%)$ calculated in relation to the mortality in the control. It was observed a high and fast larvicidal effect of deltamethrin and permethrin against these defoliator species. These insecticides however, were not efficient against the adults of these species and showed low selectivity in relation to other insects, mainly parasitoid tlies.
\end{abstract}

Key-words: Lepidoptera, control, monitoring of insects, Nystalea nyseus. Thyrinteina arnobia, deltamethrin, permethrin.

\section{INTRODUÇÃO}

A grande expansão do cultivo do Eucalyptus (FAO, 1979) parece ter possibilitado a adaptação, a essas plantas, de espécies fitófagas nativas, como os lepidópteros desfolhadores, o que foi confirmado, segundo OHMART \& EDUARDS (1991), na China, Índia, Nova Zelândia, Papua Nova Guiné e Sumatra. No Brasil, ZANUNCIO (1976) reporta que insetos-praga de mirtáceas nativas se encontravam em processo de adaptação ao eucalipto,

1 Universidade Federal de Viçosa. Departamento de Biologia Animal, 36571 -000 Viçosa, MG. 2 Jari Celulose S.A. Almerim, 68240-000 Monte Dourado, PA.

3 Universidade Federal de Viçosa. Departamento de Biologia Animal 36571-(000 Viçosa, MG. 
talvez pelo fato dessas plantas hospedeiras serem filogeneticamente próximas ao eucalipto.

As pragas Thyrinteina arnobia (Stoll, 1782) (Lepidoptera: Geometridae) e Nystalea nyseus (Cramer, 1775) (Lepidoptera: Notodontidae) são consideradas, respectivamente, praga primária e secundária do eucalipto (ZANUNCIO et al., 1990; 1991a,b).

Para conter os surtos de lagartas desfolhadoras é, as vezes, necessária a utilização de inseticidas. Frente ao primeiro surto de $T$. arnobia no Brasil, os diversos experimentos de controle químico apontaram como solução a aplicação de DDT, inicialmente feita com equipamentos terrestres e posteriormente com equipamentos aéreos (BARBIELLINE, 1950; PIGATTI et al., 1962). A partir de então, houve uma grande evolução no controle químico de lagartas desfolhadoras culminando com o atual emprego de Bacillus thuringiensis e deltametrina no controle dessas (ZANUNCIO et al., 1992).

A vantagem do uso de piretróides, como a deltametrina, em relação aos bioinseticidas, como $B$. thuringiensis, é seu grande efeito de impacto sobre a população de lagartas. A eficiência dos piretróides sobre várias pragas, reportada inicialmente por ELLIOTT et al., (1978), tem sido amplamente confirmada inclusive em lagartas desfolhadoras, em que não só a deltametrina, mas também a permetrina parecem ter grande potencial de utilização (ROBERTSON et al., 1976; ZANUNCIO et al., 1992).
Os piretróides, além de serem pouco tóxicos a animais de sangue quente, tem mostrado boa seletividade em favor de inimigos naturais de insetos fitófagos (WILKINSON et al., 1979; YU, 1988 e GUEDES et al., 1992). Em virtude desses fatores fez-se a presente pesquisa onde se buscou investigar a eficiência dos piretróides deltametrina e permetrina, contra lagartas desfolhadoras de eucalipto em região de trópico úmido.

\section{MATERIAL E MÉTODOS}

Esse trabalho foi conduzido em plantação de Eucalyptus urophylla pertencente à Jari Celulose S.A., Pará, em surtos de $T$. arnobia e $N$. nyseus. A altura média das plantas era de 3,5 $\mathrm{m}$ e o espaçamento $3 \times 2 \mathrm{~m}$. Os inseticidas utilizados foram deltametrina $\mathrm{e}$ permetrina nas dosagens mostradas na tabela 1, utilizando-se, ainda, um tratamento-testemunha onde não foi aplicado inseticida e cuja mortalidade de insetos nele verificada foi usada para corrigir os valores dos tratamentos anteriores. $\mathrm{O}$ delineamento experimental adotado foi o de blocos casualizados em arranjo fatorial $6 \times 3$ (6 aplicações

Tabela 1. Relação dos inseticidas, e suas dosagens. utilizados na composição dos diferentes tratamentos. Monte Dourado, Pará

\begin{tabular}{lllll}
\hline N* & \multicolumn{1}{c}{ INSETICIDA } & $\begin{array}{c}\text { DOSAGEM } \\
\text { (ml/ha) }\end{array}$ & OBSERvAÇÃO \\
\hline 1 & Deltametrina $25 \mathrm{CE}$ & 100,00 & com chuva** \\
2 & Deltametrina $25 \mathrm{CE}$ & 200,00 & com chuva** \\
3 & Deltametrina $25 \mathrm{CE}$ & 100,00 & sem chuva \\
4 & Deltametrina $25 \mathrm{CE}$ & 200,00 & sem chuva \\
5 & Permetrina $500 \mathrm{CE}$ & 50,00 & sem chuva \\
6 & Permetrina $500 \mathrm{CE}$ & 100,00 & sem chuva \\
\hline
\end{tabular}

- Espalhante adesivo a $0,1 \%$ utilizado em lodas as aplicaçర̃es -. Após a aplicação desses compostos, choveu $8,5 \mathrm{~mm}$ por 10 minulos na àrea. 
inseticidas $x 3$ períodos de avaliação) e quatro blocos. Cada bloco correspondeu a uma fileira partindo-se do ponto de aplicação até cerca de 20 m. A área útil de cada parcela constituiu-se de uma fileira de plantas com $18 \mathrm{~m}$ de comprimento com bordaduras de $45 \mathrm{~m}$.

As pulverizações foram terrestres com equipamento tracionado por trator. As avaliações foram feitas em cinco pontos distintos dentro de cada parcela. Nesses pontos, eram estendidas mantas plásticas de $2,0 \mathrm{~m}^{2}$ sob a copa das árvores, e nestas foram feitas as contagens dos insetos mortos 24,48 e 72 horas após aplicações inseticidas. Posterior à última avaliação, foi realizada uma pulverização a alta dosagem na área, com $500 \mathrm{ml} / \mathrm{ha}$ de malation $50 \mathrm{CE}+$ $500 \mathrm{ml} /$ ha de permetrina $500 \mathrm{CE}$, para determinar o número total de insetos em cada ponto de avaliação e calcular a porcentagem de mortalidade, devidamente corrigida pela mortalidade ocorrida na testemunha. As médias dos tratamentos foram comparadas pelo teste de Tukey a nível de confiabilidade de $5,0 \%$.

\section{RESULTADOS E DISCUSSÃO}

A eficiência dos inseticidas, nos diferentes períodos de avaliação, para lagartas e adultos de T. annobia, $N$. nyseus e outros insetos, principalmente moscas parasitóides, está representada nas tabelas 2, 3, 4 e 5, respectivamente. As análises de variância, para cada um desses grupos de insetos, mostrou ter sido significativo o efeito de bloco, exceto para o grupo das mariposas. Isso comprova a importância da determinação do alcance da pulverização, do equipamento utilizado e do estabelecimento de áreas de sobreposição nas faixas subsequentes de pulverização. As mariposas são menos sujeitas a essa variação na distribuição de inseticidas,

Tabela 2. Eficiência relativa de deltametrina e permetrina em Thrrinteina arnobia, em três período de avaliação. Monte Dourado, Pará

\begin{tabular}{|c|c|c|c|c|c|}
\hline \multirow[t]{2}{*}{ TRATAMENTO } & \multicolumn{3}{|c|}{$\begin{array}{l}\text { Periodo de Avaliaçâo } \\
\text { (Horas após Aplicação) }\end{array}$} & \multicolumn{2}{|c|}{$\begin{array}{l}\text { Número } \\
\text { Total de insetos }\end{array}$} \\
\hline & 24 & 48 & 72 & $x$ & \\
\hline 1 & 73,97 & 94.53 & 89,77 & $89,09 a^{\circ}$ & 70 \\
\hline 2 & 31.41 & 31.41 & 36.79 & $33,20 d$ & 50 \\
\hline 3 & 57,44 & 62,75 & 68,46 & $62,88 \mathrm{bc}$ & 89 \\
\hline 4 & 56,33 & 57.01 & 67,17 & $60.17 \mathrm{C}$ & 162 \\
\hline 5 & 78.55 & 79.13 & 97,33 & $85,00 \mathrm{ab}$ & 93 \\
\hline 6 & 83,65 & 85,62 & 86,29 & $85.19 \mathrm{ab}$ & 285 \\
\hline
\end{tabular}

- Medias seguidas de mesma letra nào diferem significativamente entre si $5 \%$ pelo teste de Tukey.

Tabela 3. Eficiência relativa de deltametrina e permetrina contra Nystalea nyseus, em três período de avaliação. Monte Dourado, Pará.

\begin{tabular}{|c|c|c|c|c|}
\hline \multirow[t]{2}{*}{ Tratamento } & \multicolumn{3}{|c|}{$\begin{array}{l}\text { Periodo de Avaliação } \\
\text { (Horas após Aplicaçào) }\end{array}$} & \multirow[t]{2}{*}{$\begin{array}{c}\text { Número } \\
\text { Total de Insetos }\end{array}$} \\
\hline & 24 & 48 & 72 & \\
\hline 1 & $66,71 \mathrm{~A}^{*} \mathrm{a}^{* *}$ & $83,11 \mathrm{Aa}$ & $88,87 \mathrm{Aa}$ & 736 \\
\hline 2 & $30,05 \mathrm{Ab}$ & $33.97 \mathrm{Ab}$ & $42.57 \mathrm{Ab}$ & 994 \\
\hline 3 & $85,91 \mathrm{Aa}$ & $89.97 \mathrm{~A}$ & $91,77 \mathrm{Aa}$ & 1577 \\
\hline 4 & $54,87 \mathrm{Bab}$ & $60,44 \mathrm{Bab}$ & $86,82 \mathrm{Aa}$ & 2637 \\
\hline 5 & $79,99 \mathrm{Aa}$ & $86,28 \mathrm{Aa}$ & $83,15 \mathrm{Aa}$ & 2070 \\
\hline 6 & $80,28 \mathrm{Aa}$ & $85,28 \mathrm{Aa}$ & $97,35 \mathrm{Aa}$ & 1493 \\
\hline
\end{tabular}

- Médias seguidas da mesma letra maiusscula, na mesma linha. nāo diferem significativamente entre si a $5 \%$ pelo teste de Tukey.

". Médias seguidas da mesma letra minúscula, na mesma coluna, não diterem signilicativamente entre si a $5 \%$ pelo teste de Tukey

provavelmente, devido a sua maior mobilidade.

Para três dos quatro grupos de insetos estudados, não houve diferença significativa entre a rapidez de ação dos inseticidas utilizados, exceção cabendo à deltametrina a $200 \mathrm{ml}$ (sem chuva) e as em aplicações feitas sem ação posterior de chuva. Esse fato era esperado devida à grande ação de impacto dos piretróides 
relatada por ELLIOT et al., (1978) e evidenciada por ZANUNCIO et al., (1992) em T. arnobia. O desvio desse padrão observado na mortalidade de $N$. nyseus por deltametrina aplicado a 200 $\mathrm{ml} / \mathrm{ha}$ deve ter sido casual. Nas mariposas o fato pode ser explicado pela maior possibilidade de "escape" aos inseticidas, justamente em virtude da sua maior mobilidade, hipótese reforçada

Tabela 4. Eficiência relativa de deltametrina e permetrina contra mariposas de Thryrinteina arnobia e Nystalea nyseus, em três períodos de avaliação. Monte Dourado, Pará.

\begin{tabular}{|c|c|c|c|c|}
\hline \multirow[t]{2}{*}{ TRATAMENTO } & \multicolumn{3}{|c|}{$\begin{array}{l}\text { Periodo de Avaliaçāo } \\
\text { (Horas após Aplicaçāo) }\end{array}$} & \multirow[t]{2}{*}{$\begin{array}{c}\text { Número } \\
\text { Total de Insetos }\end{array}$} \\
\hline & 24 & 48 & 72 & \\
\hline 1 & $11,59 \mathrm{~A}^{*} \mathrm{a}^{* *}$ & $15,43 \mathrm{Aa}$ & $28,67 \mathrm{Aa}$ & 69 \\
\hline 2 & $6,63 \mathrm{Aa}$ & $13,23 \mathrm{Aa}$ & $28,14 \mathrm{Aa}$ & 63 \\
\hline 3 & $11,15 \mathrm{Ba}$ & $21,13 \mathrm{Ba}$ & $39.41 \mathrm{Aa}$ & 114 \\
\hline 4 & $10,08 \mathrm{Ba}$ & $11,47 \mathrm{Ba}$ & $55.85 \mathrm{Aa}$ & 119 \\
\hline 5 & $13,45 \mathrm{Ba}$ & $13,45 \mathrm{Ba}$ & $42,24 \mathrm{Aa}$ & 99 \\
\hline 6 & $16,99 \mathrm{Ba}$ & $20,92 \mathrm{Ba}$ & $43,21 \mathrm{Aa}$ & 84 \\
\hline
\end{tabular}

- Médias seguidas da mesma letra maiúscula, na mesma linha. não deferem significativamente entre si a $5 \%$ pelo teste de Tukey.

* Médias seguidas da mesma letra minúscula na mesma coluna. nāo diferem significativamente entre si a $5 \%$ pelo lesle de Tukey

Tabela 5. Eficiência relativa de deltametrina ce permetrina contra outros insetos. principalmente moscas parasitóides, em três períodos de avaliação. Monte Dourado, Pará.

\begin{tabular}{|c|c|c|c|c|c|}
\hline \multirow{3}{*}{ Tratamento } & \multicolumn{5}{|c|}{ Periodo de Avalıąâo } \\
\hline & \multicolumn{3}{|c|}{ (Horas Apòs Aplıcaçào) } & \multirow[b]{2}{*}{$x$} & \multirow[t]{2}{*}{$\begin{array}{l}\text { Numero total } \\
\text { de insetos }\end{array}$} \\
\hline & 24 & 48 & 72 & & \\
\hline 1 & 58.18 & 68,13 & 64,78 & $63.70 \mathrm{bc}$ & 126 \\
\hline 2 & 23,61 & 36.97 & 36.97 & $32.52 d$ & 89 \\
\hline 3 & 75.03 & 79.22 & 79.99 & $78.08 a$ & 165 \\
\hline 4 & 40.77 & 47.49 & 62,02 & $50,11 \mathrm{C}$ & 95 \\
\hline 5 & 74.27 & 77,28 & 79,36 & $76,97 \mathrm{ab})$ & 137 \\
\hline 6 & 51,79 & 58,34 & 71,58 & $60,57 \mathrm{bc}$ & 84 \\
\hline
\end{tabular}

- Médias seguidas da mesma letra nāo diferem significativamente entre si $5 \%$ pelo teste de Tukey.

pelo fato de que com chuva não se observou o mesmo efeito.

As lagartas de T. arnobia foram mais eficientemente controladas pela permetrina, havendo grande variabilidade de resposta à deltametrina, cuja eficiência não parece ter sido afetada pela chuva na dosagem de 100 $\mathrm{ml} / \mathrm{ha}$, ao contrário do que ocorreu com a maior dosagem usada desse inseticida. $N$. nyseus por sua vez, foi eficientemente controlada tanto pela deltametrina quanto pela permetrina e a chuva exerceu efeito adverso somente na eficiência da deltametrina a $200 \mathrm{ml} / \mathrm{ha}$. Isto pode, provavelmente, ser explicado pelo fato da chuva ter ocorrido logo após a sua aplicação. Nesse caso, a aplicação de $100 \mathrm{ml}$ de deltametrina, o primeiro tratamento implantado, permitiu maior controle das lagartas antes do início das chuvas.

Os insetos adultos (mariposas) não foram eficientemente controladas em nenhum dos tratamentos inseticidas, não diferindo esses entre si quanto ao seu efeito. Isto pode ser devido a maior ação larvicida desses compostos ou à limitações dessa metodologia na avaliação da eficiência sobre indivíduos alados. Possivelmente durante a aplicação haviam pupas no campo que não foram afetadas pelos inseticidas, permitindo a emergência de adultos o que, indiretamente, causou redução na porcentagem de eficiência dos diferentes tratamentos.

A mortalidade de outras espécies de insetos, principalmente parasitóides foi relativamente alta, indicando que os inseticidas avaliados não foram seletivos em favor desses organismos. No entanto, em outros trabalhos foi evidenciada a baixa mortalidade de percevejos predadores frente à piretróides (WILKINSON et al., 1979; YU, 1988 e GUEDES, 1992). 


\section{CONCLUSÕES}

Os resultados desse trabalho evidenciam elevada ação larvicida dos piretróides deltametrina e permetrina no controle de $T$. arnobia e de $N$. nyseus em áreas reflorestadas com $E$. urophylla em região de trópico úmido. Esses compostos contudo, não controlaram eficientemente as mariposas dessas espécies desfolhadoras, além de causar elevada mortalidade à outras espécies de insetos, principalmente moscas parasitóides. Evidenciou-se, também, a importância da determinação da área de sobreposição das faixas de aplicação de inseticidas para permitir maior uniformidade na cobertura maximizando a eficiência da aplicação.

\section{AGRADECIMENTOS}

Ao Conselho Nacional de Desenvolvimento Científico e Tecnológico $(\mathrm{CNPq})$ e à Fundação de Amparo à Pesquisa do Estado de Minas Gerais (FAPEMIG) pelas bolsas e auxílios concedidos. À Jari Celulose S.A. è à Sociedade de Investigações Florestais (SIF) pelo apoio no desenvolvimento dessa pesquisa, através do Programa Cooperativo de Manejo Integrado de Pragas Florestais (PCMIP).

\section{Bibliografia Citada}

BARBIELLINI, A. 1950. Sobre pragas de eucalipto, essencialmente lagartas. Chácaras e Quintais, 82(1):37-40.

ELLIOTT, M.; JANES, N.E.; POTTER, C. 1978. The future of pyrethroids in insect control. Ann. Rev Entonol, 23:443-69).

FA0. Eucalyptus for planting. Rome, FAO, 1979. 678p. (FAO Forestry and Forest
Products Studies 11).

GUEDES, R.N.C.; LIMA, J.O.G.; ZANUNCIO, J.C. 1992. Seletividade dos inseticidas deltametrina, fenvalerato e fenitrotiom para Podisus connexivus Bergroth, 1891 (Heteroptera:Pentatomidae). An. Soc. Entomol. Brasil, 21(3):339-46.

OHMART, C.P.: EDUARDS, P.B.1991. Insect herbivory on Eucalyptus. Ann. Rev. Entomol., 36:637-57.

PIGATTI, A.; MELLO, E.J.R.; PIGATTI, P. 1962. Seleção de inseticidas orgânicos em laboratório para combate à praga de eucalipto Thyrinteina arnobia (Stoll. 1872). $O$ Biológico, 28(5): 132-134.

ROBERTSON, J.L.; GILLETTE, N.L.; LOOK, M.; LUCAS, B.A.; LYON,R.L. 1976. Toxicity of selected insecticides applied to western spruce hudworm. J. Econ. Entomol., (69:9)-104.

WILKINSON, J.D.; BIEVER, K.D.; IGNOFFO, C.M. 1979). Synthetic pyrethroid and organophosphate insecticides against the parasitoid Apanteles marimiventris and the predators Geocoris punctipes, Hippodamia convergens, and Podisus maculiventris. J. Econ. Entomol. 72(4):473-5.

YU, S.J. 1988. Selectivity of insecticides to the spined soldier bug (Heteroptera: Pentatomidac) and its lepidopterous prey. $/$. Lion. Eintomol., 81(1):119-22.

ZANUNCIO, J.C.; FAGUNDES, M.F.: ANJOS, N.: ZANUNCIO, T.V.: CAPITANI, L.R. 1990. Levantamento e flutuaçĩo populacional de lepidópteros associados a cucaliptecultura: $\mathrm{V}$-Regiño de $\mathrm{B} \mathrm{el}$ o Oriente. Minas Gerais, junho de 1986 a maio de 1987. Rer: Anvore, 14(1):35-44.

ZANUNCIO, J.C.; BARROS, M.E.P.; SANTOS, G.P.; GASPERAZZO, W.L.: SARAIVA, R.S. 1991a. Levantamento e flutuação populacional de lepidópteros associados à eucaliptocultura: I - Região de Montes Claros, Minas Gerais, maio de 1988 a ahril de 1989. Re: (eres. 38(128):32831 .

ZANUNCIO, J.C.: SANTANA, D.L.Q.; SANTOS, G.P.: SARTÓRIO, R.C.: 
ANJOS, N. 199lb. Levantamento e flutuação populacional de lep̧idópteros, associados à eucaliptocultura: II - Região do Alto São Francisco, M. G. An. Soc. Entomol. Brasil, 20(2):284-92.
ZANUNCIO, J.C.; GUEDES, R.N.C.; CRUZ, A.P.; MOREIRA, A.M. 1992.

Eficiência de Bacillus thuringiensis e de deltametrina em aplicação aérea, para o controle de Thyrinteina arnobia (Lepidoptera: Geometridae) em eucaliptal no Pará. Acıa Amaz. 22(4):485-492. 